\title{
Anticancer properties of ester derivatives of betulin in human metastatic melanoma cells (Me-45)
}

\author{
Małgorzata Drąg-Zalesińska ${ }^{1}$, Marcin Drąg ${ }^{3}$, Marcin Poręba ${ }^{3}$, Sylwia Borska' ${ }^{1}$ Julita Kulbacka² ${ }^{*}$ \\ and Jolanta Saczko²
}

\begin{abstract}
Background: Betulinic acid and betulin are triterpenes that have anticancer properties in various types of cancer. Unfortunately, the bioavailability and the bio-distribution of betulinic acid and its metabolic precursor, betulin are very low because of poor solubility in aqueous buffers.

Methods: In this study, we examined the anticancer properties of the ester derivatives of betulin compared to their precursors in a malignant melanoma cell line. We assessed five amino acid esters of betulin. The compounds contained four basic amino acids - natural lysine (L-Lys-OH) and three of its derivatives ( $\mathrm{L}-\mathrm{Dap}-\mathrm{OH}, \mathrm{L}-\mathrm{Dab}-\mathrm{OH}$, and L-Orn-OH) —and alanine (L-Ala-OH) as a negative control (amino acid without an amine group in the side chain). The derivatives were more soluble than their precursors (betulin and betulinic acid) in water. The betulin esters were tested in the malignant melanoma cell line Me-45. To evaluate the cytotoxicity, MTT test was performed after 24, 48 and $72 \mathrm{~h}$ of incubation with the test compounds at a concentration range of $0.75-100 \mu \mathrm{M}$. For analysis of the apoptotic activity, TUNEL assay was performed. Additionally, expression of caspase-3 and PARP-1 was investigated immunocytochemically.
\end{abstract}

Results: The highest biological activity was observed with the lysine ester. The results showed that the highest cytotoxicity and the highest number of positively stained nuclei in metastatic melanoma Me-45 cells were obtained after $72 \mathrm{~h}$ of incubation with betulin derivatives containing lysine and ornithine.

Conclusions: The betulin ester derivatives showed enhanced antitumor activity compared to their non-modified precursors. Esters of betulin can be more potent anticancer agents than their precursor as a consequence of the rapid bioavailability and increased concentration in cancer cells.

Keywords: Human melanoma, Betulin derivatives, Cytotoxicity, Apoptosis

\section{Background}

Cancers are a group of diseases that involve modified cells with dysfunctional proliferation. Melanoma is the most dangerous type of skin cancer observed in clinical practice, and its incidence has increased over the past 40 years at a faster rate than any other type of cancer. Melanoma has a high mortality rate because of its

\footnotetext{
*Correspondence: julita.kulbacka@umed.wroc.pl

2 Department of Medical Biochemistry, Wroclaw Medical University,

Chałubińskiego 10, 50-368 Wroclaw, Poland

Full list of author information is available at the end of the article
}

prominent metastasis and its resistance to chemo- and radiotherapy. Currently, the standard anti-melanoma therapy is based on surgical procedures and chemo- and immunotherapy, but these methods are still ineffective. Many new anticancer drugs have been developed to treat this type of cancer. One class of drugs is the triterpenes. These compounds are abundant in natural sources and belong to a group of isoprenoids. They have a wide variety of pharmacological activities [1]. We focused on triterpenes derived from the bark of the birch: betulin and betulinic acid (the oxidation product of betulin) that showed anticancer properties. Previous in vitro 
and in vivo studies have demonstrated that betulin and betulinic acid were cytotoxic and induced apoptosis in various tumor cells [2-4]. Another report showed that betulinic acid was an extremely selective compound, which was effective in human melanoma cells in vitro and in a mouse model [5]. Moreover, these substances can induce apoptosis in different type of cancer cells by activation of the intrinsic apoptotic pathway [6, 7]. Unfortunately, both betulin and its oxidation product have very poor solubility in aqueous media, and consequently, their bio-distribution and bioavailability are limited in medical applications. However, betulin is a natural compound that is easily isolated from plant material and can be easily converted into more soluble derivatives [8]. Betulin derivatives were previously shown to have increased solubility in water [9]. Our group synthesized five amino acid esters of betulin from the bark of birch (National patent application No PL211589). First, the cytotoxicity of these derivatives was investigated using human epidermoid carcinoma cells (A431) and normal human keratinocytes $(\mathrm{HaCaT})$. The promising anticancer activity and low toxicity towards normal human keratinocytes of these esters suggested that these compounds are promising candidates for further research. Additionally, because no successful treatment for melanoma is currently available, we studied the effects of the new derivatives of betulin on a melanoma cell line.

\section{Methods}

\section{Cells and culture conditions}

A human pigmented malignant melanoma cell line was used (Me-45). This cell line was established in 1997 at the Radiobiology Department of the Center of Oncology in Gliwice, Poland (gift from Prof. M. Latocha) from a lymph node metastasis of skin melanoma from a 35-yearold female patient. The cells were grown in DMEM (Sigma) with $10 \%$ fetal bovine serum (Sigma-Aldrich) and antibiotics (antibiotic-antimycotic Stabilized, Sigma). For further studies, the cells were removed by trypsinization (Trypsin-EDTA, Sigma) and washed with PBS. The cells were grown in a humidified atmosphere at $37^{\circ} \mathrm{C}$ and $5 \% \mathrm{CO}_{2}$.

\section{Betulin and betulin derivatives exposition}

In this study, we used betulin and betulin derivatives for metastatic melanoma treatment. The structures of the compounds are shown in Fig. 1. Synthesis of these compounds was described in our previous study by DragZalesińska et al. [10]. The experimental conditions were based on our previous reports. For our studies, we used five selected betulin ester derivatives: four basic amino acids-natural lysine (L-Lys-OH) and three of its derivatives (L-Dap-OH, L-Dab-OH, and L-Orn-OH)-and alanine ( $\mathrm{L}-\mathrm{Ala}-\mathrm{OH})$ as a negative control (amino acid without amine group in side chain) [10], as well as betulin and betulinic acid. The derivatives had increased solubility in water compared to their precursors, which was described in our earlier studies [9]. Betulin-Ala- $\mathrm{NH}_{2}$ showed no significant inhibition of cellular proliferation. This result was expected because Ala is hydrophobic and does not have an amino group in the side chain, which influences the biological properties of tested derivatives. Based on our previous studies [10], 6 and $12.5 \mu \mathrm{M}$ were selected as the concentrations of all compounds for further investigation.

\section{MTT assay}

For determination of cell viability with betulin and its derivatives, MTT assay (Sigma, Germany; In Vitro Toxicology assay) was used. The cells were grown on 96-well microplates and incubated overnight to allow for attachment. The melanoma cells were incubated in all compounds for 24,48 and $72 \mathrm{~h}$ at concentrations of $0.75-100 \mu \mathrm{M}$. The MTT cytotoxicity assay is based on the colored reaction of tetrazolium salt and assesses the mitochondrial activity of the cells. Mitochondrial function was expressed as the percentage of the viable treated cells compared to the untreated control cells (without compounds and treated separately with DMSO). All experiments were independently repeated three times.

\section{Immunocytochemical evaluation of PARP-1 and caspase-3}

The apoptotic activity was assessed by immunocytochemical determination of caspase 3 and PARP-1. Immunocytochemistry analysis was performed using the $\mathrm{ABC}$ method. Cultures were harvested on 8-well microscopic slides (Thermo Scientific). After $24 \mathrm{~h}$ of exposure to betulin and betulin derivatives at concentrations of 6 and $12.5 \mu \mathrm{M}$, cells were fixed and dehydrated using $4 \%$ paraformaldehyde for $10 \mathrm{~min}$. Next, an ethanol gradient was applied. The samples were then permeabilized and blocked by incubation with $0.1 \%$ Triton X-100 (Sigma) in PBS. The proteins were visualized with a polyclonal mouse monoclonal antibody (1:100, anti-CASP-3 and PARP-1; Santa Cruz, USA Biotechnology). For conventional bright-field microscopy (peroxidase- $\mathrm{ABC}$ labeling), the samples were incubated with a diaminobenzidine$\mathrm{H}_{2} \mathrm{O}_{2}$ mixture (DAKO) to visualize the peroxidase label and counterstained with hematoxylin (Alchem, Poland) for $30 \mathrm{~s}$. The samples were analyzed with an upright light microscope (Olympus BX51, Japan). Stained cell numbers were evaluated by counting 100 cells in 3 randomly selected fields. The analysis was carried out by two independent investigators. The results were judged to be positive if staining was observed in more than $5 \%$ of the cells. The intensity of immunohistochemical staining 


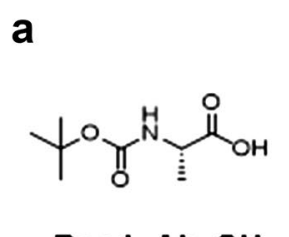

Boc-L-Ala-OH<smiles>CC(C)(C)OC(=O)NC[C@H](NC(=O)OC(C)(C)C)C(=O)O</smiles>

Boc-L-Dap(Boc)-OH

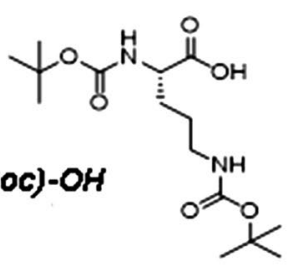

Boc-L-Dab(BOC)-OH

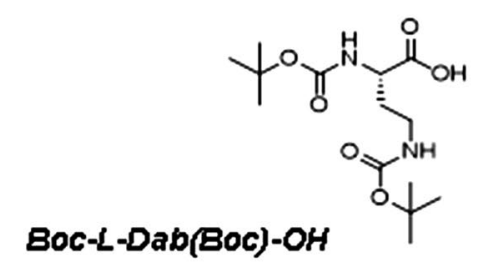

BoC-L-LyS-OH<smiles>CC(C)(C)OC(=O)NCCCC(NC(=O)OC(C)(C)C)C(=O)O</smiles>

b

Boc-L-Orn(BOC)-OH
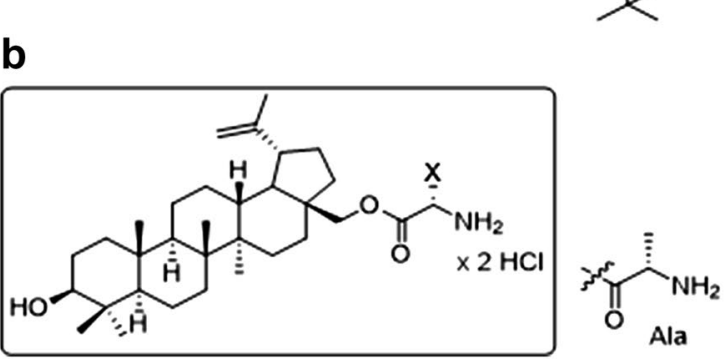
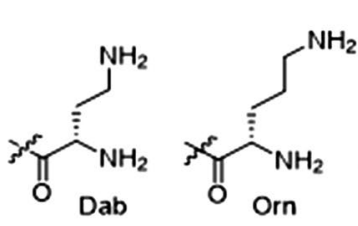

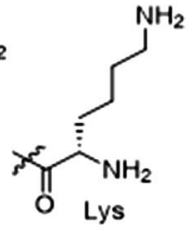

Fig. 1 Structures of betulin derivatives: a structure of amino acids used for the synthesis of betulin derivatives used for the treatment of melanoma cells (Me-45); $\mathbf{b}$ the general structure of the 5 -element collection containing L-amino acids

was evaluated as follows: $(-)$ negative, (no reaction), $(+)$ weak, $(++)$ moderate, and $(+++)$ strong. All experiments were repeated three times.

\section{TUNEL assay}

DNA fragmentation was evaluated using an ApopTag1 (Qbiogene) kit. In this method, the enzyme terminal deoxynucleotidyl transferase labels the $3-\mathrm{OH}$ ends of DNA generated during apoptosis with biotinylated nucleotides. Immunoperoxidase staining was used to detect these fragments. The apoptosis detection kit enables distinction of apoptosis from necrosis by specifically detecting the DNA cleavage and chromatin condensation associated with apoptosis. Human melanoma cells were cultured on 8-well slides (20,000 cells per slide, Roth Germany) overnight for attachment. Then, the cells were treated with the investigated compounds at concentrations of 6 and $12.5 \mu \mathrm{M}$ for $24 \mathrm{~h}$. After treatment, the cells were fixed with $4 \%$ formalin in PBS for $10 \mathrm{~min}$ and permeabilized with $0.2 \%$ Triton X-100 in PBS for 5 min at room temperature. TUNEL assay was carried out according the manufacturer's (Millipore) instructions. Nuclei were stained with hematoxylin. Then samples were mounted by DPX (Thermo Fisher Scientific, Germany) on glass slides. Cells with stained nuclei were investigated by counting 100 cells in 3 randomly selected fields. The analyses were performed by two independent investigators. Samples were evaluated with a BX51 upright light microscope (Olympus, Japan).

\section{Statistical analysis}

The significance of differences between the mean values of group of cells exposed to betulin, its derivatives and not treated control cells was assessed with test-T, which returns the probability associated with Student's $t$ test, which was carried out for each experiment individually and $n \geq 3$. $\mathrm{P} \leq 0.05\left(^{*}\right)$ was regarded as statistically significant.

\section{Results and discussion}

The resistance of many malignant cells to tumor treatment is a major problem in cancer therapy. Novel strategies are required to improve patient outcomes. Currently applied anticancer therapies are developed for inducing apoptosis or repair defects in the apoptotic pathway in cancer cells. Moreover, many cancer cells are resistant to apoptosis due to mutations in genes responsible for apoptotic death pathways [11]. Numerous anticancer strategies are based on inhibition of cell proliferation and promotion of cell death [12]. Natural compounds derived from plants are frequently used as potential anticancer substances $[13,14]$; these compounds are easily 
available because of their common occurrence in nature. Our results obtained from proliferation assay indicated that the highest cytotoxicity in metastatic Me- 45 melanoma cells was obtained after $72 \mathrm{~h}$ incubation with new betulin derivatives containing lysine and ornithine $\left(\mathrm{IC}_{50}=2.456 \mu \mathrm{M} ; \mathrm{IC}_{50}=2.465 \mu \mathrm{M}\right.$, respectively). These results were also observed for the Betulin-L-Dab- $\mathrm{NH}_{2}$ compound $\left(\mathrm{IC}_{50}=9.253 \mu \mathrm{M}\right)$ compared to the precursors betulin and betulinic acid (Fig. 2; Table 1). The available data indicate that triterpenes are a promising group of anticancer and chemopreventive agents [7, 11]. The most popular compounds from this group are betulin and betulinic acid. Numerous studies have shown that betulin and betulinic acid exhibit biological and pharmacological properties, including anticancer and chemopreventive activities [1, 8]. Additionally, they do not affect normal cells $[8,15,16]$. Unfortunately their biological properties are limited because of the poor water solubility [2]. Betulin from birch bark was modified by our research group with selected natural amino acids (national patent application, No PL211589), which had increased water solubility compared to that of betulin and betulinic acid. Our previous data confirmed that the new compounds have cytotoxic properties and proapoptotic activity in cancer cells [9].

In the current study, immunocytochemical staining of PARP-1 and caspase- 3 in melanoma cells treated with betulin compounds was performed. PARP-1 is cleaved by caspase- 3 through apoptosis, which leads to its inactivation $[8,9]$. The results from the immunocytochemical analyses of apoptotic proteins are presented in Table 2. Overexpression of PARP-1 was observed in melanoma cells after exposure to every compound: betulin and its derivatives achieved approximately 100\%. Low expression of caspase-3 ( $<5 \%$ for both concentrations) was observed for modified and non-modified substances prepared from birch bark (Table 2). Additionally, TUNEL assay was used to assess the number of apoptotic nuclei after treatment. The highest number of positively stained nuclei was observed in Me- 45 cells after incubation with betulin derivatives containing ornithine, lysine, and alanine and betulinic acid (Fig. 3). After incubation with betulin, the lowest number of apoptotic nuclei were noted (Table 3). In other studies, we examined the cytotoxicity and ability of these derivatives to induce apoptosis in skin cancer cells (A431) and normal keratinocytes (HaCaT) [10]. Our investigation suggested that selected derivatives of betulin can be also useful in the treatment of melanoma cells. The highest cytotoxicity was noted in Me-45 cells after incubation with new betulin derivatives containing lysine and ornithine. Similar results were also observed with the Betulin-L-Dab- $\mathrm{NH}_{2} \times 2 \mathrm{HCl}$ compound compared to its precursor betulin. The highest number of positively stained nuclei was obtained in Me- 45 cells after incubation with betulin derivatives containing ornithine, lysine and alanine as well as betulinic acid. After incubation with betulin, the lowest number of apoptotic nuclei were noted. In previous investigations, novel lysine esters of betulin were shown to promote apoptosis in tumor-sensitive and resistant pancreatic and stomach cell lines more effectively than betulin and betulinic acid $[2,9]$. Orchel et al. examined the effects of betulin and its acetylenic derivative 28-O-propynoylbetulin on proliferation and apoptosis in human melanoma cells (G-361). They modified betulin through insertion of a propynol motif into the betulin structure at the $\mathrm{C}-28$ position. The authors compared the cytotoxic and proapoptotic properties of betulin and its derivatives. The investigations demonstrated similar cytotoxicity, inhibition of the cell cycle and apoptosis activation in melanoma cells [7]. Additionally, Boryczka et al. showed that modified betulin at the C-28 position had stronger cytotoxic properties against human and murine leukemia cells than its precursor, an acetylenic derivative and cisplatin. However, 28-O-propynoylbetulin had less apoptotic and cytotoxic activity in breast and colorectal cancer cells [17]. Furthermore, Hata et al. [18] noted that the lupine triterpenes showed significantly increased cytotoxicity than betulin in melanoma, leukemia and neuroblastoma cells.

In our study, treatment of Me- 45 melanoma cells with the earlier described derivatives resulted in significant increases in apoptotic nuclei and strong cytotoxicity in these cells compared to cells incubated with betulin and betulinic acid. The immunocytochemical staining showed similar amounts of caspase 3 and PARP-1 after incubation with betulin and its selected derivatives. It is worth noting that we used esters of betulin with different numbers of free amino groups (one or two), which influence their solubility in water. Additionally, the biological properties and activity of these esters of betulin were positively associated with the length of the side chain of the L-amino acid.

In various studies, the cytotoxic and proapoptotic properties of betulin and betulinic acid were demonstrated in different melanoma cells. Moreover, the mechanism of this apoptotic activity was described. Betulin and betulinic acid increased the apoptosis of melanoma cells via the interaction with the mitochondrial membrane and the release of cytochrome $\mathrm{c}$ or apoptosis inducing factor (AIF). Importantly, betulinic acid induces apoptosis in cancer cells independent of their p53 status $[16,19-24]$.

Our results demonstrated that modification of betulin through the addition of selected amino acids can result in stronger cytotoxic and proapototic effects compared to betulin. As shown in our studies, esters of betulin can 

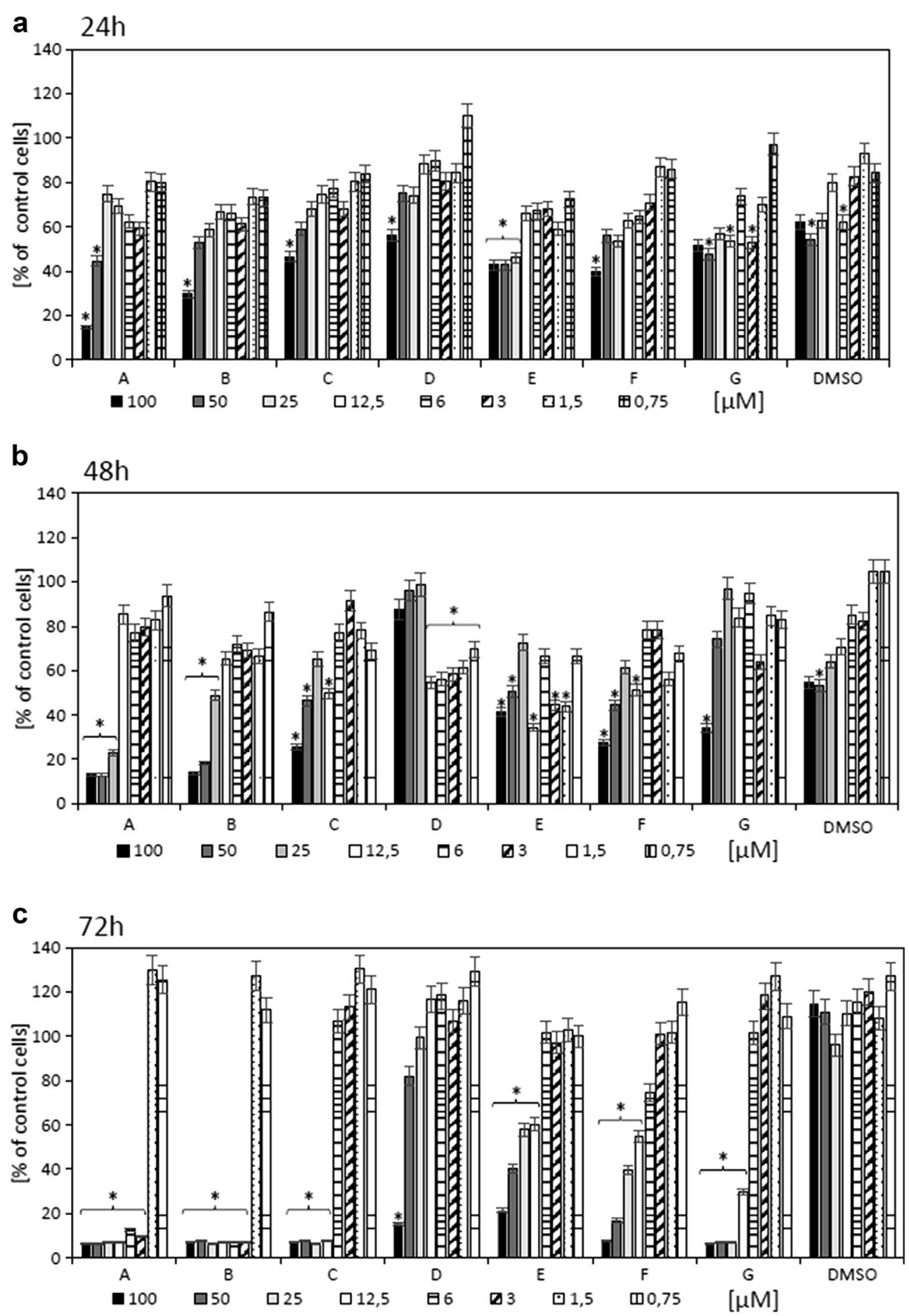

Fig. 2 The cytotoxicity studies evaluated Me45 cells treated with betulin and its new derivatives after $\mathbf{a} 24 \mathrm{~h}$; b $48 \mathrm{~h}$ and $\mathbf{c} 72 \mathrm{~h}$ where: $A$ —Betulin-

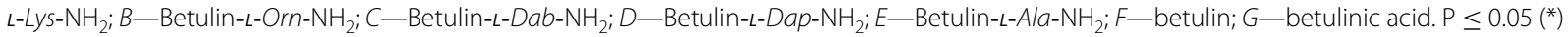

be more potent anticancer agents than their precursor as a consequence of more rapid availability and increased concentration in cancer cells. The cytotoxic and proapoptotic mechanism of these compounds may be similar to betulin and betulinic acid, but this hypothesis must be further investigated. In a future study, we will examine the mechanism of apoptosis after betulin ester treatment by evaluating the major proteins involved in this type of 
Table 1 The IC50 index and water solubility of betulin derivatives evaluated for human Me45 cells

\begin{tabular}{lrrrl}
\hline Compound & \multicolumn{3}{c}{$\mathbf{I C}_{\mathbf{5 0}}$ for Me45 cells $[\boldsymbol{\mu M}]$} & \multirow{2}{*}{ Water solubility } \\
\cline { 2 - 4 } & $\mathbf{2 4 \mathbf { h }}$ & $\mathbf{4 8} \mathbf{h}$ & $\mathbf{7 2} \mathbf{~ h}$ & \\
\hline Betulin-L-Lys-NH2 & 55.339 & 20.275 & 2.456 & Very good \\
Betulin-L-Orn-NH2 & 70.658 & 27.155 & 2.465 & Very good \\
Betulin-L-Dab-NH2 & 66.453 & 51.405 & 9.253 & Very good \\
Betulin-L-Dap-NH2 & 107.740 & 61.524 & 75.489 & Very good \\
Betulin-L-Ala-NH2 & 86.573 & 62.089 & 10.125 & Very good \\
Betulin & 24.208 & 42.822 & 30.456 & Weak \\
Betulinic acid & 22.772 & 22.794 & 15.325 & Middle \\
\hline
\end{tabular}

death. Elucidation of the apoptotic pathway induced after incubation with the analyzed compounds can help in the development of new anticancer strategies.

\section{Conclusions}

We concluded that the betulin ester derivatives efficiently enhanced antitumor activity compared to their nonmodified precursors in metastatic melanoma cells. The results indicated that natural compounds derived from betulin can be more potent anticancer agents than its precursor as a consequence of rapid bioavailability and better concentration in skin cancer cells.

Table 2 Semi-quantitative evaluation of immunocytochemical reaction with anti-PARP-1 and anti-caspase 3 antibodies in Me-45 cells after exposition to betulin derivatives, after $24 \mathrm{~h}$

\begin{tabular}{|c|c|c|c|c|}
\hline \multirow[t]{2}{*}{ Compound } & \multicolumn{4}{|l|}{ Me-45 } \\
\hline & PARP-1 $12.5 \mu \mathrm{M}$ & PARP-1 $6 \mu \mathrm{M}$ & Casp $312.5 \mu \mathrm{M}$ & Casp $36 \mu \mathrm{M}$ \\
\hline Control cells & $5 \%,+/++$ & - & $<5 \%, \mp$ & - \\
\hline Betulin-L-Lys- $\mathrm{NH}_{2}$ & $95 \%,++$ & $50 \%,+/++$ & $0 \%$ & $0 \%$ \\
\hline Betulin-L-Orn-NH ${ }_{2}$ & $100 \%,++$ & $98 \%,+/++$ & $<5 \%, \mp$ & $<5 \%, \mp$ \\
\hline Betulin-L-Dab-NH & $100 \%,+++$ & $100 \%,+++$ & $0 \%$ & $0 \%$ \\
\hline Betulin-L-Dap-NH ${ }_{2}$ & $100 \%,+++$ & $98 \%,+/++$ & $<5 \%, \mp$ & $<5 \%, \mp$ \\
\hline Betulin-L-Ala- $\mathrm{NH}_{2}$ & $100 \%,++/+++$ & $90 \%,++$ & $<5 \%, \mp$ & $0 \%$ \\
\hline Betulin & $100 \%,++/+++$ & $95 \%,++/+++$ & $10 \%,+$ & $<5 \%$,干 \\
\hline Betulinic acid & $100 \%,++/+++$ & $100 \%,++/+++$ & $5-10 \%,+/++$ & $<5 \%$, \\
\hline
\end{tabular}

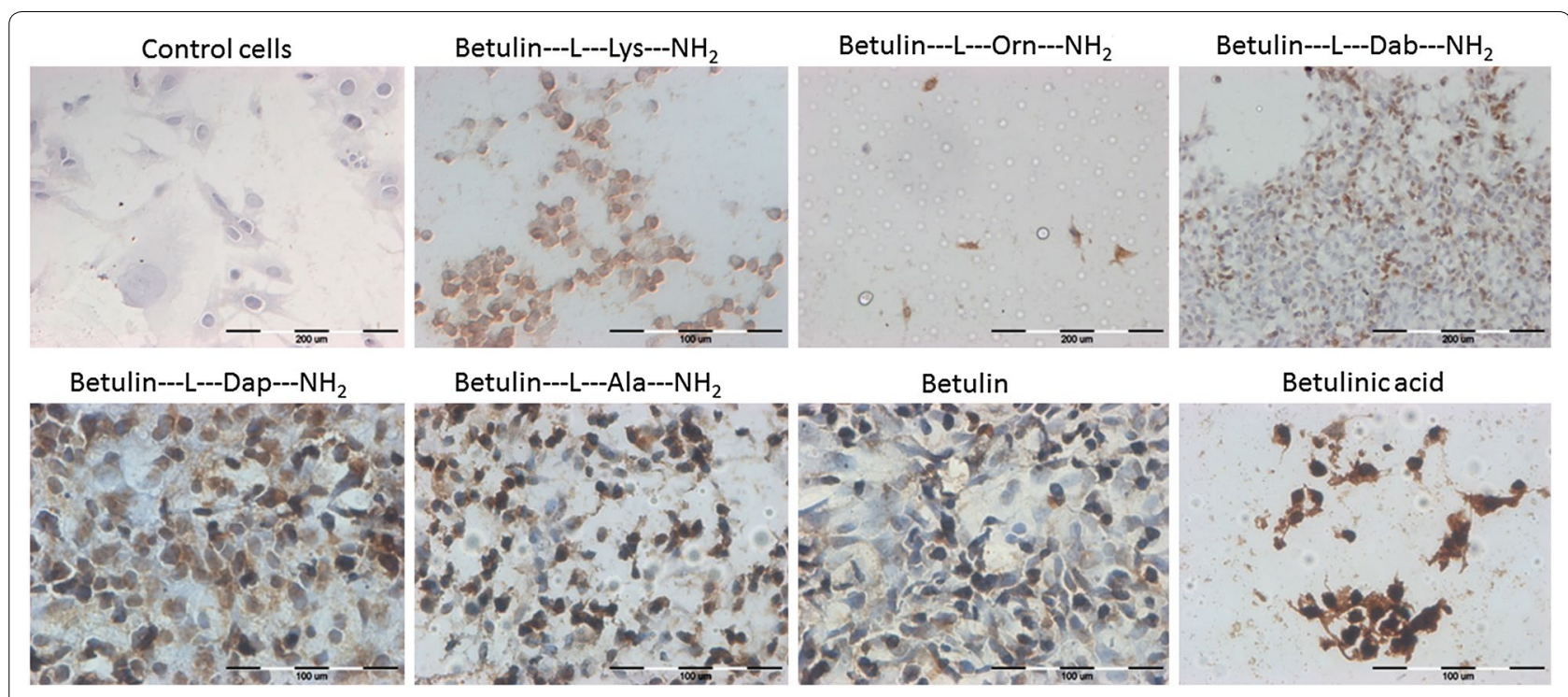

Fig. 3 Apoptotic nuclei evaluation in Me45 cells after treatment with betulin and its new derivatives at a concentration of $6 \mu M$ (TUNEL assay) $72 \mathrm{~h}$ after treatment 
Table 3 Apoptotic nuclei evaluation by TUNEL assay in Me-45 cells after exposition to betulin derivatives in concentration $6 \mu \mathrm{M}$ in $72 \mathrm{~h}$ after treatment

\begin{tabular}{ll}
\hline Compound & \% of cells with stained nuclei \\
\hline control cells & 0 \\
Betulin-L-Lys- $\mathrm{NH}_{2}$ & 86 \\
Betulin-L-Orn- $\mathrm{NH}_{2}$ & 100 (cells damage, reduced number of cells) \\
Betulin-L-Dab- $\mathrm{NH}_{2}$ & 34 \\
Betulin-L-Dap- $\mathrm{NH}_{2}$ & 48 \\
Betulin-L-Ala- $\mathrm{NH}_{2}$ & 78 \\
Betulin & 27 \\
Betulinic acid & 95 \\
\hline
\end{tabular}

\section{Abbreviations}

AIF: apoptosis inducting factor; PARP-1: poly [ADP-ribose] polymerase 1; Me-45: human metastatic melanoma; A431: human epidermoid carcinoma cells; HaCaT: human keratinoctytes; PBS: phosphate-buffered saline; DPX distrene-80, plasticizer, xylene traditional mounting medium.

\section{Authors' contributions}

MD-Z and JK designed the study. MD and MP carried out betulin derivative synthesis. JK, JS and SB performed the in vitro experiments. JK and JS analyzed the results. All authors read and approved the final manuscript.

\section{Author details}

${ }^{1}$ Department of Histology and Embryology, Wroclaw Medical University, Chałubińskiego 6a, 50-368 Wroclaw, Poland. ${ }^{2}$ Department of Medical Biochemistry, Wroclaw Medical University, Chałubińskiego 10, 50-368 Wroclaw, Poland. ${ }^{3}$ Department of Bioorganic Chemistry, Department Faculty of Chemistry, Wroclaw University of Science and Technology, Wyb. Wyspiańskiego 27, 50-368 Wroclaw, Poland.

\section{Acknowledgements}

This work was supported by the National Science Center (Poland) under Grant No. 0275/B/P01/2010/38 (M. Drąg-Zalesińska). The work was also supported by a statutory activity subsidy from the Polish Ministry of Science and Higher Education for the Faculty of Chemistry at Wroclaw University of Technology.

\section{Competing interests}

The authors declare that they have no competing interests.

\section{Funding}

This work was supported by the National Science Center (Poland) under Grant No. 0275/B/P01/2010/38 (M. Drąg-Zalesińska). The work was also supported by a statutory activity subsidy from the Polish Ministry of Science and Higher Education for the Faculty of Chemistry at Wroclaw University of Technology.

Received: 28 July 2016 Accepted: 7 December 2016

Published online: 03 January 2017

\section{References}

1. Dzubak P, Hajduch M, Vydra V, Hustova A, Kvasnica M, Biedermann D, Markova L, Urban M, Sarek J. Pharmacological activities of natural triterpenoids and their therapeutic implications. Nat Prod Rep. 2006;23(3):394-411.

2. Drag $M$, Surowiak P, Drag-Zalesinska M, Dietel M, Lage $H$, Oleksyszyn J. Comparison of the cytotoxic effects of birch bark extract, betulin and betulinic acid towards human gastric carcinoma and pancreatic carcinoma drug-sensitive and drug-resistant cell lines. Molecules. 2009;14(4):1639-51
3. Laszczyk M, Jager S, Simon Hearhaus B, Sheffler A, Schempp CM. Physical, chemical and pharmacological characterization of a new oleogelforming triterpene extract from the outer bark of birch. Planta Med. 2006;72:1389-95

4. Galgon T, Wohlrab W, Drager B. Betulinic acid induces apoptosis in skin cancer cells and differentiation in normal human keratinocytes. Exp Dermatol. 2005;14:736-43.

5. Pisha $\mathrm{E}, \mathrm{Chai} H$, Lee IS. Discovery of betulinic acid as a selective inhibitor of human melanoma that functions by induction of apoptosis. Nat Med. 1995;1:1046-51.

6. Li Y, Shen JT, Gao C, Li Q, Jin YH. Caspase-9 activation-criti-cal for betulin-induced apoptosis of human hepatoma cells. Chem Res Chin Univ. 2010;26:792-7.

7. Orchel A, Kulczycka A, Chodurek E, Bębenek E, Borkowska P, Boryczka S, Kowalski J, Dzierżewicz Z. Influence of betulin and 28-O-propynoylbetulin on proliferation and apoptosis of human melanoma cells (G-361). Postepy Hig Med Dosw (Online). 2014;6(68):191-7.

8. Alakurtti S, Makela T, Koskimies S, Yli-Kauhaluoma J. Pharmacological properties of the ubiquitous natural product betulin. Eur J Pharm Sci. 2006;29(1):1-13.

9. Drag-Zalesinska M, Kulbacka J, Saczko J, Wysocka T, Zabel M, Surowiak P. Drag M. Esters of betulin and betulinic acid with amino acids have improved water solubility and are selectively cytotoxic toward cancer cells. Bioorg Med Chem Lett. 2009;19(16):4814-7.

10. Drąg-Zalesińska M, Wysocka T, Borska S, Drąg M, Poręba M, Choromańska A, Kulbacka J, Saczko J. The new esters derivatives of betulin and betulinic acid in epidermoid squamous carcinoma treatment - In vitro studies. Biomed Pharmacother. 2015;72:91-7.

11. Maxwell SA, Davis GE. Differential gene expression in p53-mediated apoptosisresistant vs apoptosis-sensitive tumor cell lines. Proc Natl Acad Sci USA. 2000;97(24):13009-14.

12. Indran IR, Tufo GS, Pervaiz C. Brenner, recent advances in apoptosis, mitochondria and drug resistance in cancer cells. Biochim Biophys Acta. 2011;1807(6):735-45

13. Król SK, Kiełbus M, Rivero-Müller A, Stepulak A. Comprehensive review on betulin as a potent anticancer agent. Biomed Res Int. 2015;2015:584189.

14. Newman DJ, Cragg GM, Snader KM. The influence of natural products upon drug discovery. Nat Prod Rep. 2000;17(3):215-34.

15. Zuco V, Supino R, Righetti SC, Cleris L, Marchesi E, Gambacorti-Passerini C, Formelli F. Selective cytotoxicity of betulinic acid on tumor cell lines, but not on normal cells. Cancer Lett. 2002;175:17-25.

16. Ciurlea SA, Dehelean CA, Ionescu D, Berko S, Csanyi E, Hadaruga DI, Ganta S, Amiji MM. A comparative study regarding melanoma activity of betulinic acid on topical ointment vs. systemic nanoemulsion delivery systems. J Agroaliment Process Technol. 2010;16:420-6.

17. Boryczka S, Bębenek E, Wietrzyk J, Kempińska K, Jastrzębska M, Kusz J, Nowak M. Synthesis, structure and cytotoxic activity of new acetylenic derivatives of betulin. Molecules. 2013;18:4526-43.

18. Hata K, Hori K, Takahashi S. Differentiation- and apoptosis-inducing activities by pentacyclic triterpenes on a mouse melanoma cell line. J Nat Prod. 2002;65:645-8

19. Fulda S, Debatin KM. Betulinic acid induces apoptosis through a direct effect on mitochondria in neuroectodermal tumors. Med Pediatr Oncol. 2000;35:616-8

20. Li Y, He K, Huang Y, Zheng D, Gao C, Cui L, Jin YH. Betulin induces mitochondrial cytochrome $\mathrm{c}$ release associated apoptosis in human cancer cells. Mol Carcinog. 2010:49:630-40.

21. Periasamy G, Teketelew G, Gebrelibanos M, Sintayehu B, Gebrehiwot M, Karim A, Geremedhin G. Betulinic acid and its derivatives as anti-cancer agent: a review. Arch Appl Sci Res. 2014;6:47-58.

22. Kim DS, Pezzuto JM, Pisha E. Synthesis of betulinic acid derivatives with activity against human melanoma. Bioorg Med Chem Lett. 1998;8(13):1707-12.

23. Selzer E, Pimentel E, Wacheck V, Schlegel W, Pehamberger H, Jansen B, Kodym R. Effects of betulinic acid alone and in combination with irradiation in human melanoma cells. J Invest Dermatol. 2000;114:935-40.

24. Salti Gl, Kichina JV, Das Gupta TK, Uddin S, Bratescu L, Pezzuto JM, Mehta RG, Constantinou Al. Betulinic acid reduces ultraviolet-C-induced DNA breakage in congenital melanocytic naeval cells: evidence for a potential role as a chemopreventive agent. Melanoma Res. 2001;11:99-104. 